\title{
Biomedical Pollutants in the Urban Environment and Implications for Public Health: A Case Study
}

\author{
Jeffrey N. T. Squire \\ International Development Program, School of Environment, Enterprise and Development (SEED), Faculty of Environment, \\ University of Waterloo, 200 University Avenue, Waterloo, ON, Canada N2L 3G1
}

Correspondence should be addressed to Jeffrey N. T. Squire; jnsquire@uwaterloo.ca

Received 13 March 2013; Accepted 8 April 2013

Academic Editors: J. Konde-Lule, M. H. Stigler, and R. Y. Wang

Copyright (c) 2013 Jeffrey N. T. Squire. This is an open access article distributed under the Creative Commons Attribution License, which permits unrestricted use, distribution, and reproduction in any medium, provided the original work is properly cited.

\begin{abstract}
This study investigated the management of biomedical pollutants in the Accra Metropolitan Area in Ghana, using a qualitative case study approach involving interviews, focus-group discussions, and observation techniques. A state of precariousness was found to characterize the management of biomedical pollutants in the study area, culminating in the magnification of risks to the environment and public health. There is neither a single sanitary landfill nor a properly functioning incineration system in the entire metropolis, and most of the healthcare facilities surveyed lack access to suitable treatment technologies. As a result, crude burning and indiscriminate dumping of infectious and toxic biomedical residues were found to be widespread. The crude burning of toxic biomedical pollutants was found to provide environmental pathways for carcinogenic substances. These include polynuclear aromatic hydrocarbons (PAHs), polychlorinated dibenzofurans (PCDFs), polychlorinated dibenzopara-dioxins (PCDDs), polychlorinated biphenyls (PCBs), hydrogen, lead, mercury, cadmium, chlorobenzenes, particulate matter, and chlorophenols. The improper disposal of biomedical pollutants in open dumps and unsanitary landfills also carries a risk of providing environmental entry points for volatile organic compounds (VOCs), inorganic macrocomponents, heavy metals, and xenobiotic organic compounds.
\end{abstract}

\section{Introduction}

Biomedical pollutants generated during the course of healthcare delivery are known to carry greater risks to the environment and human health due to its infectious, hazardous, and toxic composition [1-3]. Some classes of biomedical pollutants can interfere with the metabolic processes of organisms, cause neurotoxic, nephrotoxic, and neurological effects on the human body, and stop or kill the growth of living cells [3]. Certain classes of biomedical pollutants are also known to be bioactive in aquatic ecosystems even at low concentrations and can have negative impacts on aquatic life in terms of reproduction and development [46]. In spite of the risks, the management of healthcare biomedical pollutants is not prioritized in many parts of the world especially in developing countries. In many developing countries, there are no effective policies in place regulating the management of biomedical pollutants, resulting in unsafe handling and disposal practices. In cases where there are policies in place, compliance and enforcement procedures are highly negligible [7-9]. Resultantly, the management of biomedical pollutants in many developing countries is characterized by gross inefficiencies, contributing to the magnification of risks to the environment and public health [10-14].

This study investigates the management of healthcare biomedical pollutants in the Accra Metropolitan Area in Ghana. To date, not much is known or understood about the situation since past studies have mainly focused on the issue of municipal solid wastes creating a gap in the literature. The current study aims at bridging that gap by providing an empirical analysis of systemic and institutional approaches to the management of biomedical pollutants in the study area.

\section{Materials and Methods}

The Accra Metropolitan Area is the largest city in Ghana covering a total land area of 200 square kilometres. Originally, 
the native homeland of the chiefs and people of the $G a$ traditional area; the metropolis has a population of four million people (including daily commuters), with an estimated annual growth rate of $3.4 \%$ [15]. The metropolis is constituted of eleven submetropolitan districts, namely, Ablekuma Central, Ablekuma North, Ablekuma South, Ashiedu Keteke, Ayawaso Central, Ayawaso East, Ayawaso West Wuogon, La, Okaikoi North, Okaikoi South, and Osu Klottey. Each of the submetropolitan districts is headed by an elected assembly person. As a local government body, the Accra Metropolitan Assembly is headed by a Metropolitan Chief Executive who is appointed by the Executive branch of the central government. Of the total 466 healthcare facilities in the entire Greater Accra Region, 218 are located in the Accra Metropolitan Area. The management of biomedical pollutants generated in these healthcare facilities is the primary responsibility of the Accra Metropolitan Assembly which operates through its Waste Management Department. The mandate of the Accra Metropolitan Assembly is enshrined in Legislative Instrument 1500 (L. I. 1500) of Local Government Act, 1993.

The data for the study was collated in a three-month period from January to March, 2010. The data collection methods include interviews, group discussions, and observation techniques. In all, twenty-five informants representing key stakeholders selected from a pool of healthcare providers, waste management service providers, and local as well as national level government officials in the study area were interviewed in a semistructured format. Interviewees were selected through purposive sampling, and those who demonstrated a fair knowledge of the subject matter were invited to participate in the research. Focus-group discussions involving frontline staff of various healthcare facilities, waste management service providers, and civil service employees were also conducted as part of the study. Participants were selected randomly, and in all, three focus-group discussion sessions were held at a mutually agreed upon location. The principal objective of the informal group discussions was to ascertain first-hand approaches to the management of biomedical pollutants at the institutional level. Additionally, site visits were made to 10 healthcare facilities as well as two waste dumps in Accra. In order to obtain a balanced view of the situation in the study area, five of the healthcare facilities surveyed were government operated, while the other five were private owned. Due to reasons of confidentiality, none of the individuals or healthcare facilities surveyed during the research are identified in this study. A triangulation process involving the verification of information provided by informants ensured the collection of high quality data from a variety of sources. In order to ensure free and unhindered data collection process, participants were given the opportunity to refuse or withdraw their participation at any time during the research. The data was then initially transcribed, content analyzed, carefully organized, opencoded, and analyzed for common themes. The analyses of the human health impacts were facilitated by means of secondary data mainly, literature pertaining to biomedical pollutants generated during the course of healthcare activities.

\section{Results and Discussion}

3.1. Legislative Arrangements. As a local government body, the Accra Metropolitan Authority does not have specific frameworks that regulate the management of biomedical wastes generated in the metropolis. However, legal provisions were found to exist at the national level and enshrined in the Environmental Sanitation Policy (ESP) of Ghana. The ESP requires generators and handlers of biomedical pollutants to adopt safe and effective management practices in accordance with recommendations provided by the local government. The site observations revealed that the policy directives outlined in the ESP are not routinely applied in the study area due to a number of factors including lack of awareness, resource constraints, lax enforcement, and lack of training.

3.2. Segregation. Segregation of different classes of biomedical pollutants in the AMA was found to be inefficient and highly problematic. Segregation practices tend to be limited to certain classes of pollutants mainly human anatomical parts. This was found to be prevalent in nine out of the ten healthcare facilities surveyed. Only four of the ten healthcare facilities practiced source separation of sharp objects such as needles, scalpels, and blades. In most cases, segregation practices were found to be inconsistent accross various wards and departments. Some wards segregated sharp wastes, while others within the same facility did not. In all ten healthcare facilities, all biomedical pollutants with the exception of human anatomical parts are commingled during the collection and transportation process. In one particular healthcare facility, segregation was found to be carried out at the hospital's central storage unit by sanitation workers for the purpose of recovering materials for onward sale to junk buyers. On-site sterilization of recovered materials from biomedical pollutants was not observed, a point substantiated by the interviews. The nonsegregation of biomedical pollutants from other types of wastes can contribute to environmental contamination which in turn can lead to adverse public health repercussions.

3.3. On-Site Storage. On-site storage of biomedical pollutants in the AMA was also found to be laden with major problems in all ten healthcare facilities surveyed. In general, the primary method of storing needles, blades, blood-soaked bandages, and scalpels within individual wards in all ten facilities is by means of cardboard boxes, old metal buckets, and metal bins. In all ten healthcare facilities, anatomical wastes were stored separately from the rest of the biomedical pollutants, while all other classes of biomedical pollutants were commingled. Only three healthcare facilities used standard puncture proof containers for waste storage although this was not consistent across the various wards. In one government-operated healthcare facility, sharp objects were stored in standard puncture proof containers in one ward, and in cardboard boxes in another. A similar situation was observed in several private healthcare facilities where sharp objects were stored in metal containers in one ward and plastic containers in another. In all cases, storage bins used for 
the storage of anatomical parts inside of the wards were found to be lined with plastic bags to avoid spillage. On the contrary, storage bins used for the storage of nonanatomical residue in 9 out of ten healthcare facilities were found to have no plastic lining or colour-coded storage bags. Outside of the wards, biomedical pollutants are stored in large metal or plastic drums. This was found in nine healthcare facilities. Only two healthcare facilities within the government sector had access to secure on-site storage facilities although both were found to be abandoned and in poor condition. Such poor storage practices contribute to the magnification of risks to the environment and public health. To offset such challenges, it is highly recommended that healthcare facilities must have safe and secured on-site storage facilities [3]. Evidently, this is not the situation in the study area.

The improper storage of potentially infectious and hazardous biomedical pollutants in the study area poses major environmental, occupational, and public health risks. Scavenging by both humans and vectors can bring about adverse public health repercussions including exposure to pathogenic microorganisms and potentially toxic chemicals. The rudimentary storage of sharp objects in cardboard boxes may also cause accidents and infections.

3.4. Transportation. The process of transporting biomedical pollutants from one point to another within all ten healthcare facilities surveyed in the AMA is by means of manual lifting and wheelbarrows. The interviews revealed that offsite transportation of biomedical pollutants in one government healthcare facility has been contracted to three waste management service providers in the formal sector. These waste management service providers are required to use special vehicles and disinfection practices although this was not found to be the case. In many instances informal sector waste management service providers known in the local parlance as "kaya-boorla," literally translated meaning waste labourers, were found to be engaged in the transportation of biomedical pollutants. These informal sector service providers use four-wheel nonmechanized trolleys, wheelbarrows, and cane baskets in the collection of biomedical pollutants and operate mainly in healthcare facilities located in residential areas and slums in the metropolis. Such practices are inconsistent with recommendations outlined in the literature that requires healthcare facilities to use designated trolleys, containers, carts and motorized vehicles for the transportation of biomedical pollutants [3].

3.5. Treatment. Generally, all ten healthcare facilities surveyed in the AMA do not practice effective treatment of biomedical pollutants prior to disposal. Only two of the ten healthcare facilities surveyed in the AMA were found to practice treatment of biomedical pollutants prior to final disposal although large measures of inconsistencies were observed. In one particular healthcare facility, it was observed that infectious biomedical pollutants, particularly anatomical residues, were encapsulated prior to disposal. However, liquid biomedical pollutants including blood products are emptied directly into the drain without treatment. Only two healthcare facilities were found to have autoclaves and microwaves for treating biomedical pollutants prior to disposal although most are not utilized. Only one out of the ten healthcare facilities was found to use needle destruction technologies. In one particular facility, waste water from the hospitals main mortuary is emptied directly into the municipal drain without treatment. The presence of solid wastes in the drains has caused the waste water to be stagnated. Domestic livestock including goats and poultry were observed drinking from the drain after feeding on an open dump located adjacent to the mortuary.

The nontreatment of biomedical pollutants prior to disposal carries several implications for the environment and public health. Exposure to certain types of untreated biomedical pollutants may stop or kill the growth of certain living cells and have detrimental effects on the liver, kidneys, and nerve system in the human body [3]. Some classes of biomedical pollutants can also cause ionization of intracellular proteins and proteinaceous components in the human body and in the process affect neurological development [3]. Biomedical pollutants containing high contents of heavy metals such as lead and silver have the potential to cause adverse neurotoxic and nephrotoxic effects in the human body [3].

3.6. Rudimentary Incineration and Crude Burning. Rudimentary incineration and crude burning of biomedical pollutants were found to be prevalent in all ten healthcare facilities surveyed. Only two government healthcare facilities have access to on-site incineration technologies, while none of the private institutions have access to incineration technology. Most of the incineration technologies in government institutions were found to be in obsolete condition and operated in a rudimentary fashion or were simply inoperable. In one of the government-operated healthcare facilities, two separate incinerators were observed. One of the incinerators is used specifically for the treatment of anatomical residue, while the other is used for other types of biomedical pollutants. Both incinerators were found to be in obsolete condition and generate significant volumes of ash. Additionally, there was no air filtering system installed on any of the incinerators resulting in the emission of thick clouds of smoke during incineration. The mephitis odour around the vicinity of some hospital incinerators was conspicuous, raising major concerns regarding cleaning and disinfection procedures. One of the incinerators is located on an open dump, and the presence of both mobile and stationary food and drinking water vendors were observed in close proximity. In one of the healthcare facilities, it was learnt that the on-site incinerator has been broken down for several years. Resultantly, the incineration rooms have been converted to human living and storage quarters, and some workers were observed relaxing in spaces designated for incineration or in close proximity. The interviews revealed that the Ministry of Health has directed all private healthcare facilities to transport their infectious wastes to larger government facilities for incineration. However, none of the private healthcare providers 
interviewed during the research follows this government directive citing lack of resources. It was also uncovered during the site observation that incineration technologies at larger government healthcare facilities were inoperable. As a result of the lack of proper incineration technologies, crude burning of biomedical pollutants was found to be prevalent in healthcare institutions surveyed in the AMA. In some cases biomedical pollutants are burnt in metal containers located at the back of the facility.

The crude and rudimentary burning of biomedical pollutants containing heavy metals are likely to contribute to the discharge of dangerous gases and particulates into the environment. These include polynuclear aromatic hydrocarbons, polychlorinated dibenzofurans, polychlorinated dibenzopara-dioxins polychlorinated biphenyls, hydrogen, lead, mercury, cadmium, chlorobenzenes, particulate matter, and chlorophenols [16, 17]. There is some empirical evidence suggesting a direct correlation between such air pollutants and adverse effect on the health of humans [18, 19] and livestock [20]. Ryder [19] conducted a study on the effects of incinerators on human health and concluded that people living within one kilometre of municipal solid waste incinerators suffered significant increases in all cancers, including a 37-percent increase in liver cancers.

3.7. On-Site Open Dumping. On-site open dumping of biomedical pollutants was found to be practiced in all of the healthcare facilities surveyed. The wastes deposited in onsite dumps are regularly burnt to reduce volume and toxicity. A close observation of on-site dumps in several healthcare facilities revealed the presence of partially burnt biomedical residue, such as blood soaked bandages, hypodermic needles, and discarded pharmaceutical products. In one instance, discarded human anatomical parts wrapped in polythene bags were found on an on-site dump where a rudimentary incinerator was located. It emerged during the study that onsite open dumping of human anatomical residue wrapped in plastic bags is also a common practice in private healthcare facilities located in residential areas. In most cases anatomical wastes generated during abortion and other surgical procedures are wrapped in polythene bags and placed on the curbside to be transported by waste carriers. Liquid biomedical pollutants such as blood and bodily fluids are routinely emptied into residential septic tanks without prior treatment. Most of the on-site dumps visited during the study were located in close proximity to human settlements and food vendors. The presence of domestic livestock scavenging for food and drinking from above-ground drains filled with liquid biomedical residue in healthcare facilities were also observed during the study.

The improper disposal of untreated liquid biomedical pollutants in drains carries severe risks to the environment including the pollution of surface, ground, and drinking water sources. Certain types of biomedical pollutants are known to be bioactive even at low concentrations and can be nondegradable in the environment $[4,5]$. This can have both short-and long-term deleterious effects on the environment and potentially human health. Similarly, the disposal of sharp objects, including used needles, syringes, blades, knives, saws, scalpels, or glass materials in open dumps poses risk of needle-stick injuries and infections to humans and wildlife.

\section{Conclusion}

Demonstrably, the management of biomedical pollutants in the study area is in a state of precariousness, culminating in the magnification of risks to the environment and public health. Pathways for environmental contamination and human health infections include ineffective storage, transportation, incineration, and unsafe disposal practices. Ameliorating existing conditions in the study area is pivotal for the mitigation of risks to the environment and public health. Essentially, the following recommendations are deemed worthy of consideration.

(i) Need for effective and enforceable legislations for biomedical pollutants at the local level.

(ii) Mandated treatment of biomedical wastes in all healthcare facilities.

(iii) Source separation of biomedical wastes from other types of waste.

(iv) Mandatory training and awareness programs for all stakeholders involved in the generation and management of biomedical wastes.

(v) Safe disposal practices.

(vi) Raising public awareness through environmental education.

This study posits that the above recommendations coupled with investments in adequate waste management infrastructures will go a long way in improving the precarious conditions in the Accra Metropolitan Area.

\section{Acknowledgment}

This study was funded in part by an AUCC/CIDA Students for Development Internship Award.

\section{References}

[1] E. L. Burke, "A survey of recent literature on medical waste," Journal of Environmental Health, vol. 56, no. 9, pp. 11-14, 1994.

[2] P. Klangsin and A. K. Harding, "Medical waste treatment and disposal methods used by hospitals in Oregon, Washington, and Idaho," Journal of the Air and Waste Management Association, vol. 48, no. 6, pp. 516-526, 1998.

[3] A. Pruss, E. Giroult, and P. Rushbrook, Eds., Safe Management of Wastes from Health-Care Activities, World Health Organization, Geneva, Switzerland, 1999.

[4] C. E. Purdom, P. A. Hardiman, V. J. Bye, N. C. Eno, C. R. Tyler, and J. R. Sumpter, "Estrogenic effects of effluents from sewage treatment works," Chemical Ecology, vol. 8, pp. 275-285, 1994.

[5] C. G. Daughton and T. A. Ternes, "Pharmaceuticals and personal care products in the environment: agents of subtle change?" Environmental Health Perspectives, vol. 107, no. 6, pp. 907-938, 1999. 
[6] S. Jobling, M. Nolan, C. R. Tyler, G. Brighty, and J. P. Sumpter, "Widespread sexual disruption in wild fish," Environmental Science and Technology, vol. 32, no. 17, pp. 2498-2506, 1998.

[7] S. V. Manyele, "Effects of improper hospital-waste management on occupational health and safety," African Newsletter on Occupational Health and Safety, vol. 14, pp. 30-33, 2004.

[8] B. Mbongwe, B. T. Mmereki, and A. Magashula, "Healthcare waste management: current practices in selected healthcare facilities, Botswana," Waste Management, vol. 28, no. 1, pp. 226233, 2008.

[9] M. McLean, H. K. Watson, and A. Muswema, "Veterinary waste disposal: practice and policy in Durban, South Africa (20012003)," Waste Management, vol. 27, no. 7, pp. 902-911, 2007.

[10] B. E. Bassey, M. O. Benka-Coker, and H. S. A. Aluyi, "Characterization and management of solid medical wastes in the federal capital territory, Abuja Nigeria," African Health Sciences, vol. 6, no. 1, pp. 59-63, 2006.

[11] M. M. Hassan, S. A. Ahmed, K. A. Rahman, and T. K. Biswas, "Pattern of medical waste management: existing scenario in Dhaka City, Bangladesh," BMC Public Health, vol. 8, article 36, 2008.

[12] R. R. A. M. Mato and G. R. Kassenga, "A study on problems of management of medical solid wastes in Dar es Salaam and their remedial measures," Resources, Conservation and Recycling, vol. 21, no. 1, pp. 1-16, 1997.

[13] A. Coker, A. Sangodoyin, M. Sridhar, C. Booth, P. Olomolaiye, and F. Hammond, "Medical waste management in Ibadan, Nigeria: obstacles and prospects," Waste Management, vol. 29, no. 2, pp. 804-811, 2009.

[14] S. Gupta and R. Boojh, "Report: biomedical waste management practices at Balrampur Hospital, Lucknow, India," Waste Management and Research, vol. 24, no. 6, pp. 584-591, 2006.

[15] R. Grant and P. Yankson, “Accra," Cities, vol. 20, no. 1, pp. 65-74, 2003.

[16] M. Bakoğlu, A. Karademir, and S. Ayberk, "An evaluation of the occupational health risks to workers in a hazardous waste incinerator," Journal of Occupational Health, vol. 46, no. 2, pp. 156-164, 2004.

[17] Y. A. Levendis, A. Atal, J. B. Carlson, and M. Del Mar Esperanza Quintana, "Pah and soot emissions from burning components of medical waste: examination/surgical gloves and cotton pads," Chemosphere, vol. 42, no. 5-7, pp. 775-783, 2001.

[18] E. Enger and B. Smith, Environmental Science: A Study of Interrelationships, McGraw Hillninth, 2004.

[19] R. Ryder, "“Sustainable" incineration and death by dioxin," The Ecologist, vol. 27, no. 4, pp. 135-136, 1997.

[20] O. L. Lloyd, M. M. Lloyd, F. L. R. Williams, and A. Lawson, "Twinning in human populations and in cattle exposed to air pollution from incinerators," British Journal of Industrial Medicine, vol. 45, no. 8, pp. 556-560, 1988. 


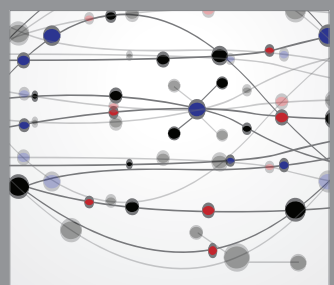

The Scientific World Journal
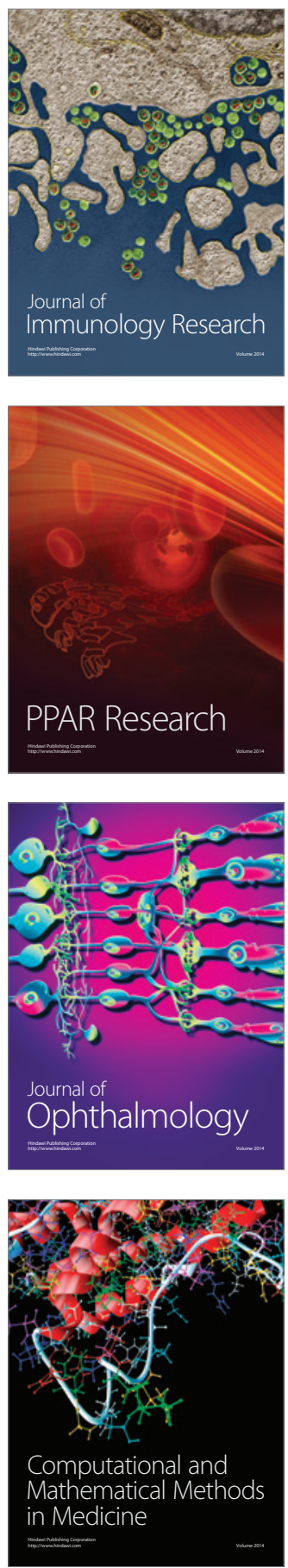

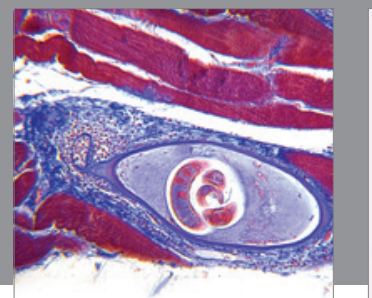

Gastroenterology

Research and Practice
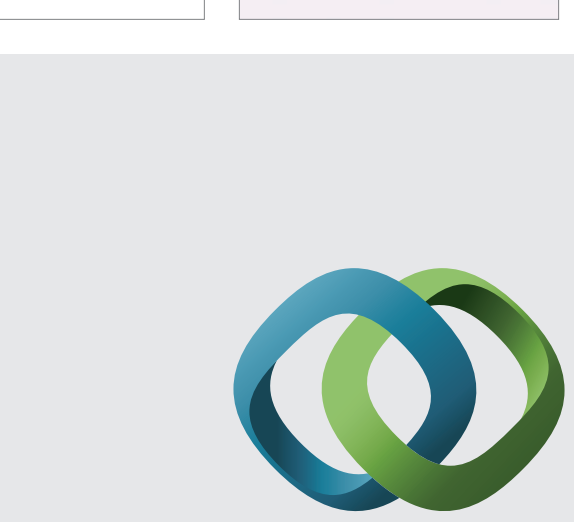

\section{Hindawi}

Submit your manuscripts at

http://www.hindawi.com
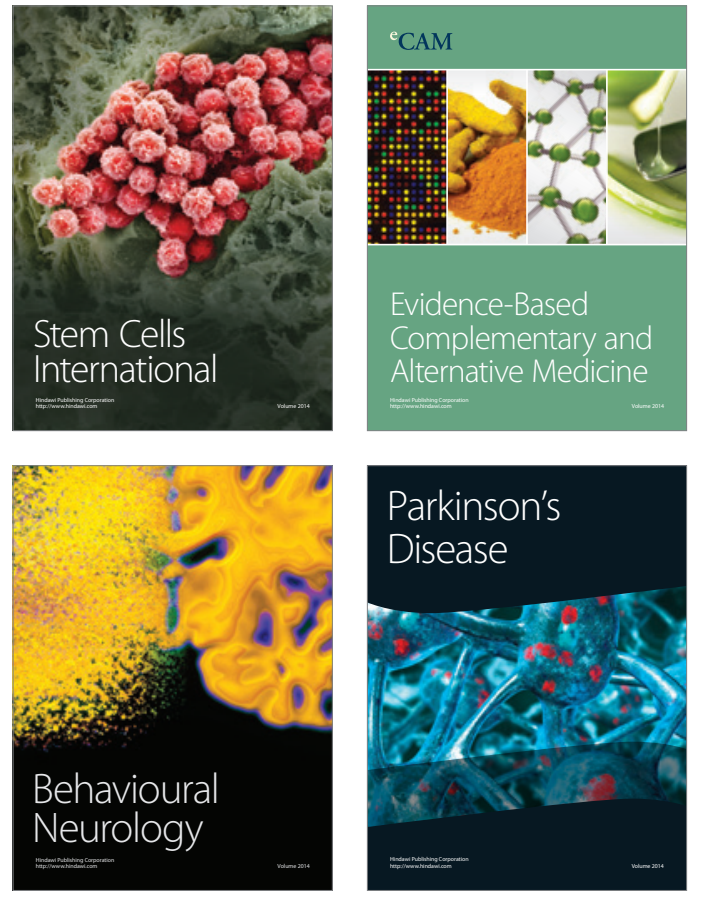
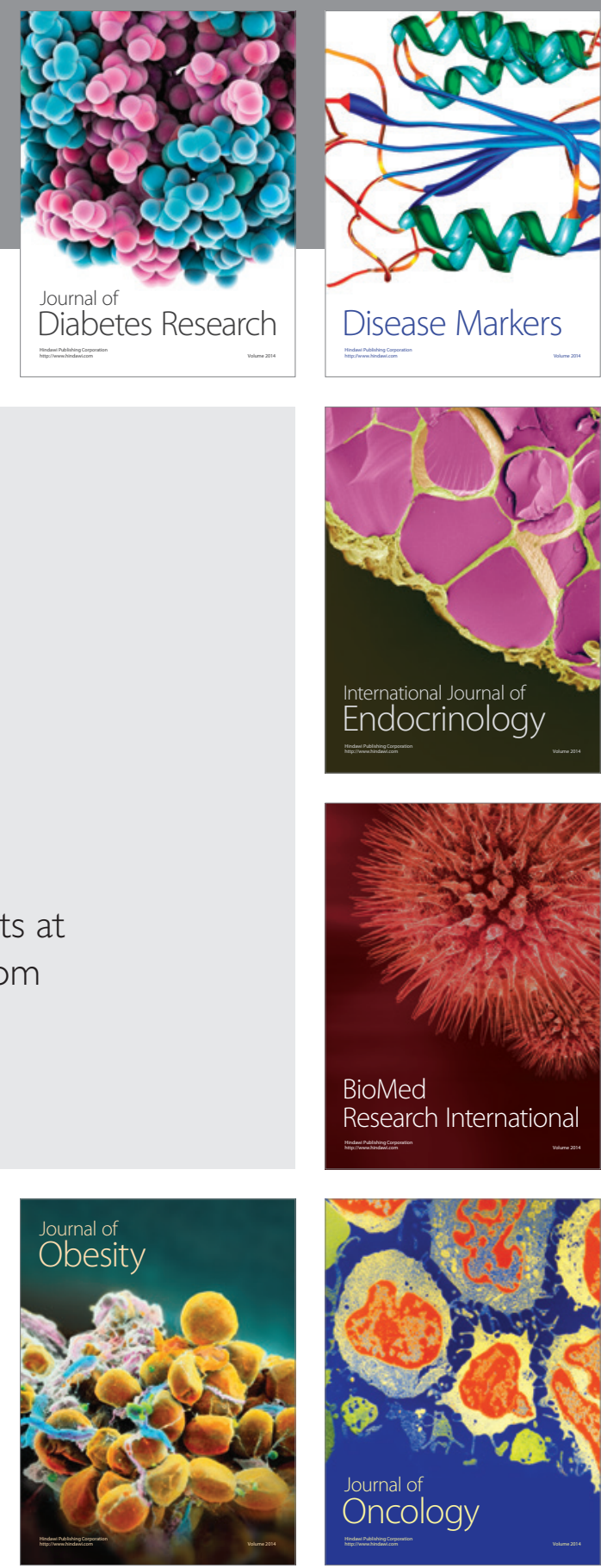

Disease Markers
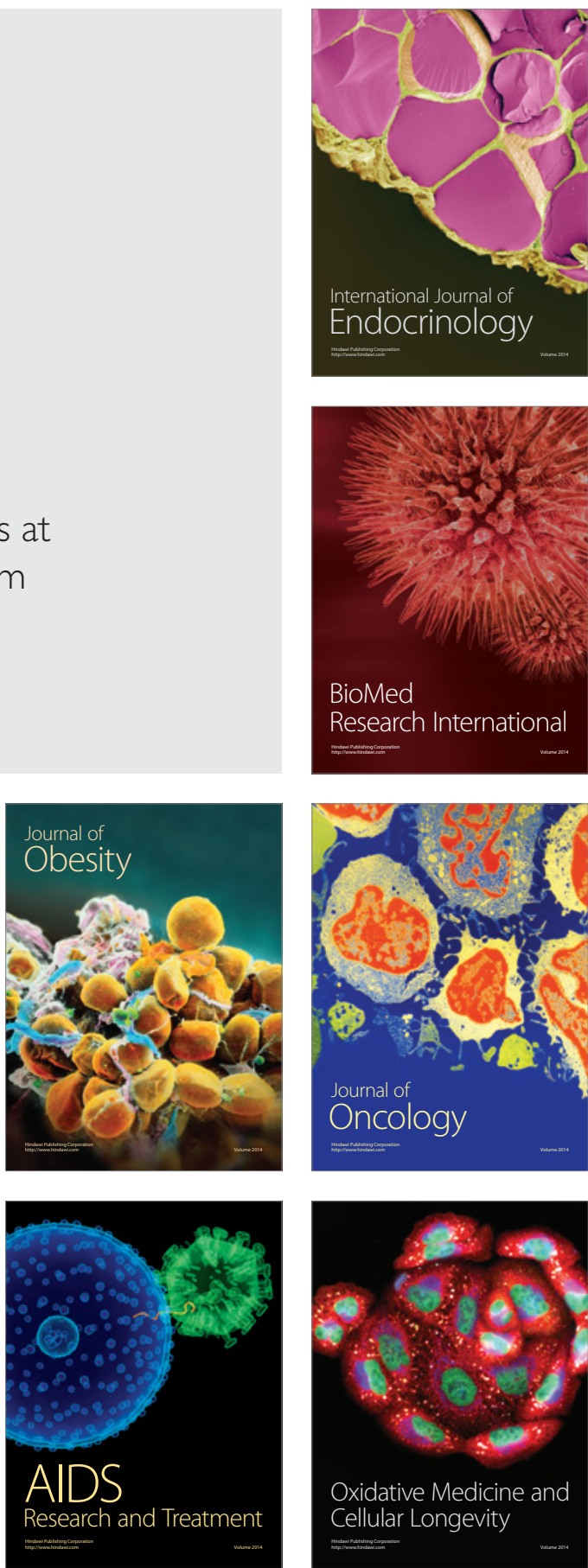